\title{
Talega SynCon - Power Grid Support for Renewable-based Systems
}

Nguyen, Ha Thi; Guerriero, Cesar; Yang, Guangya; Bolton, Christopher J.; Rahman, Tariq ; Jensen, Peter Højgaard

Published in:

Proceedings of Western Protective Relay Conference 2018

Publication date:

2018

Document Version

Peer reviewed version

Link back to DTU Orbit

Citation (APA):

Nguyen, H. T., Guerriero, C., Yang, G., Bolton, C. J., Rahman, T., \& Jensen, P. H. (2018). Talega SynCon Power Grid Support for Renewable-based Systems. In Proceedings of Western Protective Relay Conference 2018

\section{General rights}

Copyright and moral rights for the publications made accessible in the public portal are retained by the authors and/or other copyright owners and it is a condition of accessing publications that users recognise and abide by the legal requirements associated with these rights.

- Users may download and print one copy of any publication from the public portal for the purpose of private study or research.

- You may not further distribute the material or use it for any profit-making activity or commercial gain

- You may freely distribute the URL identifying the publication in the public portal

If you believe that this document breaches copyright please contact us providing details, and we will remove access to the work immediately and investigate your claim. 


\title{
Talega SynCon - Power Grid Support for Renewable-based Systems
}

\author{
Ha Thi Nguyen, Cesar Guerriero, Guangya Yang, Christopher J Bolton, Tariq Rahman, and Peter Højgaard Jensen
}

\begin{abstract}
Toward the renewable energy era where the electricity is based $100 \%$ on renewable energy sources, the power systems are experiencing operational challenges due to lack of short-circuit power and inertia support. This may cause a cascade failure or even a collapse of the whole system. In addressing this issue, synchronous condenser as a reborn technology which not only supports voltage regulation but also supplies inertial response and short-circuit power for the systems. This paper validates the synchronous condenser benefit at Talega substation in southern California which is equipped with a modern and advanced control technology for synchronous condensers. Based on the measurement data from phasor measurement unit (PMU), it can be concluded that synchronous condenser is a critical key for the system frequency stability improvement and short-circuit power support of renewable-based systems.
\end{abstract}

Keywords-Inertial response, renewable-based systems, shortcircuit power, synchronous condenser, voltage regulation.

\section{INTRODUCTION}

Renewable energy sources have achieved strong popularity over the past decade, generating $22 \%$ of the total global energy consumption by 2013 and becoming much more prominent in the total world's energy supply. By 2020, the amount of global electricity generation coming from renewable energy will be over $26 \%$ higher than today's combined electricity demand of China, India, and Brazil [1]. Deployment continues to shift toward energy-hungry emerging markets. Installed renewable sources (wind and solar) in California is rapidly growing and is becoming an important source of the future power generation portfolio.

High-level power electronic-based generation penetration makes the system operation more challenging due to lack of short-circuit power and inertia support. Traditional power plants are usually huge synchronous generators which are capable of providing ancillary services for balancing and transient characteristics. On the contrary, most of renewable energy generators are interfaced to the grid through power electronic converters which have different characteristics and

\footnotetext{
Ha Thi Nguyen and Guangya Yang are with the Center for Electric Power and Energy, Department of Electrical Engineering, Technical University of Denmark, Kgs. Lyngby, Denmark (e-mail: thangu@elektro.dtu.dk; gyy@elektro.dtu.dk).

Cesar Guerriero is with Siemens US, Raleigh, NC USA (e-mail: cesar.guerriero@siemens.com).

Christopher $\mathrm{J}$ Bolton and Tariq Rahman are with San Diego Gas and Electric SDG\&E company, San Diego, CA USA (e-mail: CBolton@semprautilities.com; TRahman@semprautilities.com).

Peter Højgaard Jensen is with Siemens A/S, Ballerup, Denmark (e-mail: peter_hoejgaard.jensen@siemens.com).
}

are often controlled in such a way independent of the system frequency.

Comprehensive reviews on the renewable energy impact on the United State power system operation are presented in [2], [3]. Maintaining sufficient inertia in the system to guarantee operational security is the main challenge of the Nordic power system [4]. Recently, 1200-MW solar photovoltaic (PV) resources in the Southern California system disconnected based on a perceived system frequency below $57 \mathrm{~Hz}$ which was due to the phase locked loop indicating a near instantaneous frequency during the transient/distorted waveform period as less than the threshold [5]. Obviously, the low inertia issue of the modern system has been generally recognized.

To guarantee the secure operation, strict grid codes regarding frequency response and headroom requirements have been issued by California ISO [6], as well as the renewable generation integration standards are investigated in [7].

Synchronous condenser (SC) has been playing a key role in keeping voltage stability through reactive power regulation in conventional power systems for a couple of decades [8], [9], [10]. In addition, $\mathrm{SC}$ is an alternator that can provide inherently inertial response due to the electromagnetic coupling with the grid. The kinetic energy stored in its rotating mass that can naturally counteract the frequency change during disturbances. To tackle the detrimental effect of renewable resources on grid $\mathrm{SC}$ is proposed as a potential solution for low inertia systems to support inertia and short-circuit power [11], [12], [13]. In order to maintain the proper short circuit ratio at the converter station in Jeju Island, two new $13.2 \mathrm{kV},+50 /-25$ Mvar synchronous condensers are installed for stability of the HVDC control [14].

Awareness of the importance of inertia and short-circuit power support of the future renewable-based system, San Diego Gas and Electric SDG\&E company has been installing seven synchronous condensers commissioned by Siemens company in the California system for voltage regulation, inertia and short-circuit support.

This paper validates the synchronous condenser benefit at Talega substation in Southern California where first two units equipped with a modern and advanced control technology were commissioned. Based on the data collected from phasor measurement unit (PMU) of a transmission line trip and an amount of solar PV resource disconnection incident, the performance of synchronous condensers in terms of fast inertia support, reactive power regulation, and short-circuit capability during disturbances is validated. The measurement data clearly shows that not only the reactive power rapidly increases to minimize the voltage drop, but also the kinetic energy available as the active power quickly react against the frequency excursions during incidents. It can be concluded that SC is a critical key 


\begin{tabular}{|c|c|c|c|}
\hline Today's Outlook & Supply & Emissions & AS OF $12: 0505 / 31 / 2018$ \\
\hline Supply and renewables & & & View official data in OASIS \\
\hline & & & ڤ \\
\hline $\begin{array}{l}25,067 \mathrm{MW} \\
\text { Current demand }\end{array}$ & $\begin{array}{c}15,509 \mathrm{MW} \\
\text { Current renewables }\end{array}$ & $\begin{array}{c}10,464 \mathrm{MW} \\
\text { Current solar }\end{array}$ & $\begin{array}{l}3,134 \mathrm{MW} \\
\text { Current wind }\end{array}$ \\
\hline
\end{tabular}

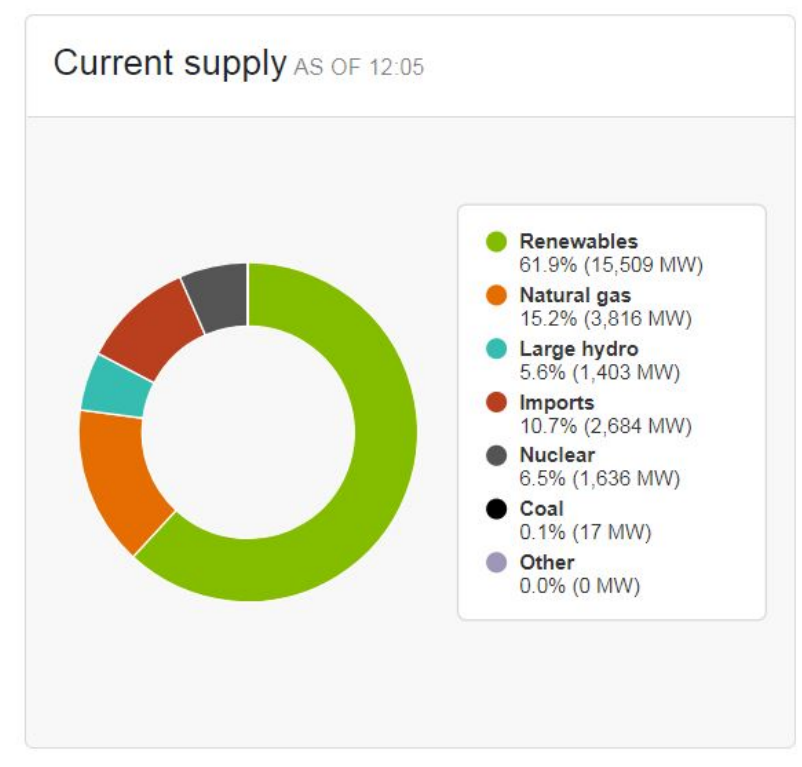

Fig. 1. California supply outlook. (Collected on May 31, 2018)

to the system frequency stability improvement and short-circuit power support of renewable-based systems.

The rest of the paper is organized as follows: section II depicts the impact of high-level penetration of renewable energy on system frequency stability and how synchronous condensers operate to improve the frequency stability. The measurement data from PMU with different event records is analyzed to evaluate the synchronous condenser performance in section III. Some important conclusions are drawn in section IV.

\section{SYNCHRONOUS CONDENSER FOR FREQUENCY STABILITY ENHANCEMENT}

A. Impact of high penetration of renewable energy sources on system frequency

In order to maintain the power system operational security, the system frequency must be within the acceptable range of grid codes. If the frequency is out of the predefined range, protection systems start activating to protect machines and electric equipment which may cause sudden imbalances in generation and demand. This makes frequency deviation arise

\section{Current renewables AS OF 12:05}

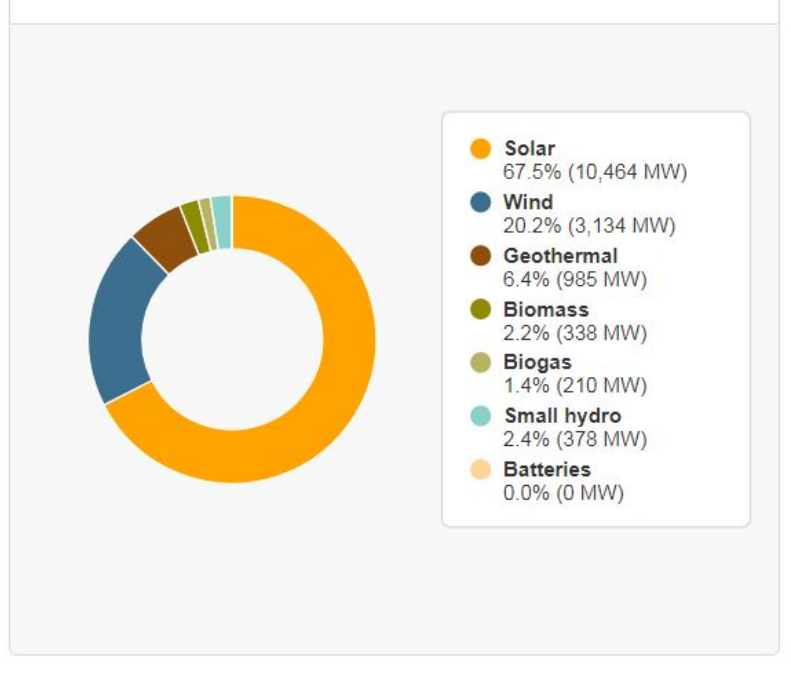

to an unacceptable level, the disconnection of generation like renewable generators or HVDC links, and loads is resulted in, which may lead to a cascade effect or even system collapse.

System inertia is defined as the resistance to changes in system frequency by storing and injecting kinetic energy into the system which comes from synchronously connected rotating machines. Higher system inertia makes the system stronger that can handle transient changes in system frequency and helps in stabilizing the system. Lower system inertia increases the likelihood of sharp system changes and instability arising from progressively small disturbances that could lead to severe faults.

The system inertia of a power system is referred to the nominal apparent power of synchronous machines that is defined by

$$
H_{\text {sys }}=\frac{\sum_{i=1}^{N}\left(S_{n i} H_{i}\right)}{S_{\text {sys }}}
$$

where $S_{\text {sys }}$ is selected equal to the total load of system; N is the number of synchronous machines; and $S_{n i}$ and $H_{i}$ are the nominal apparent power and the inertia constant of $i$-th 
(a) ROCOF

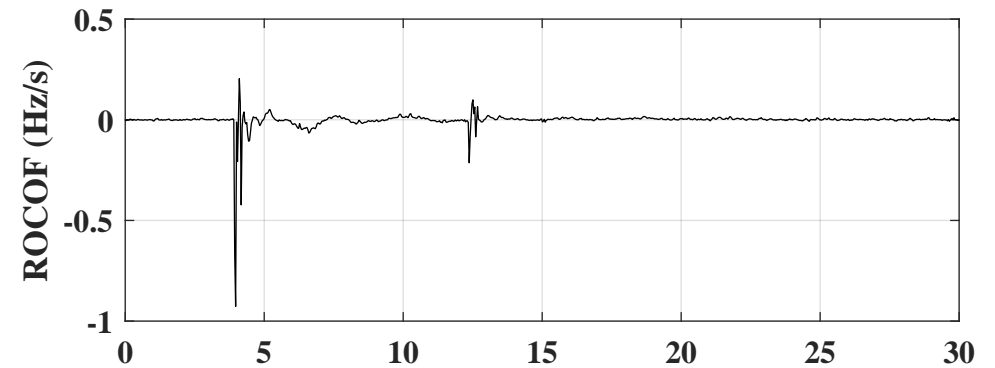

(b) Frequency

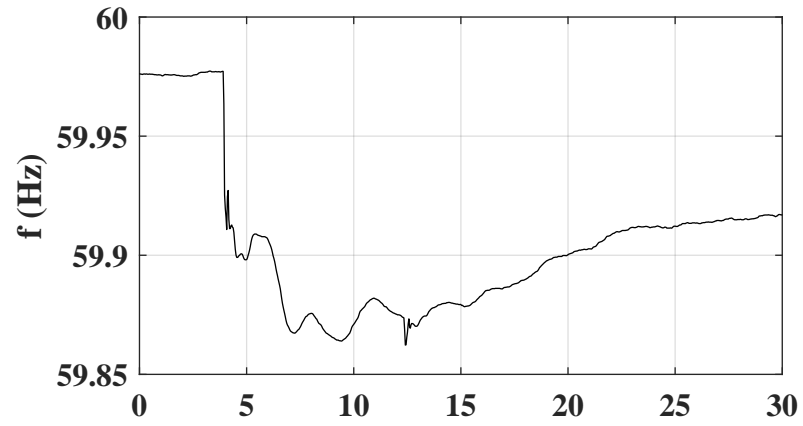

t (s)

(c) Reactive Power of SCs

(d) Active Power of SCs
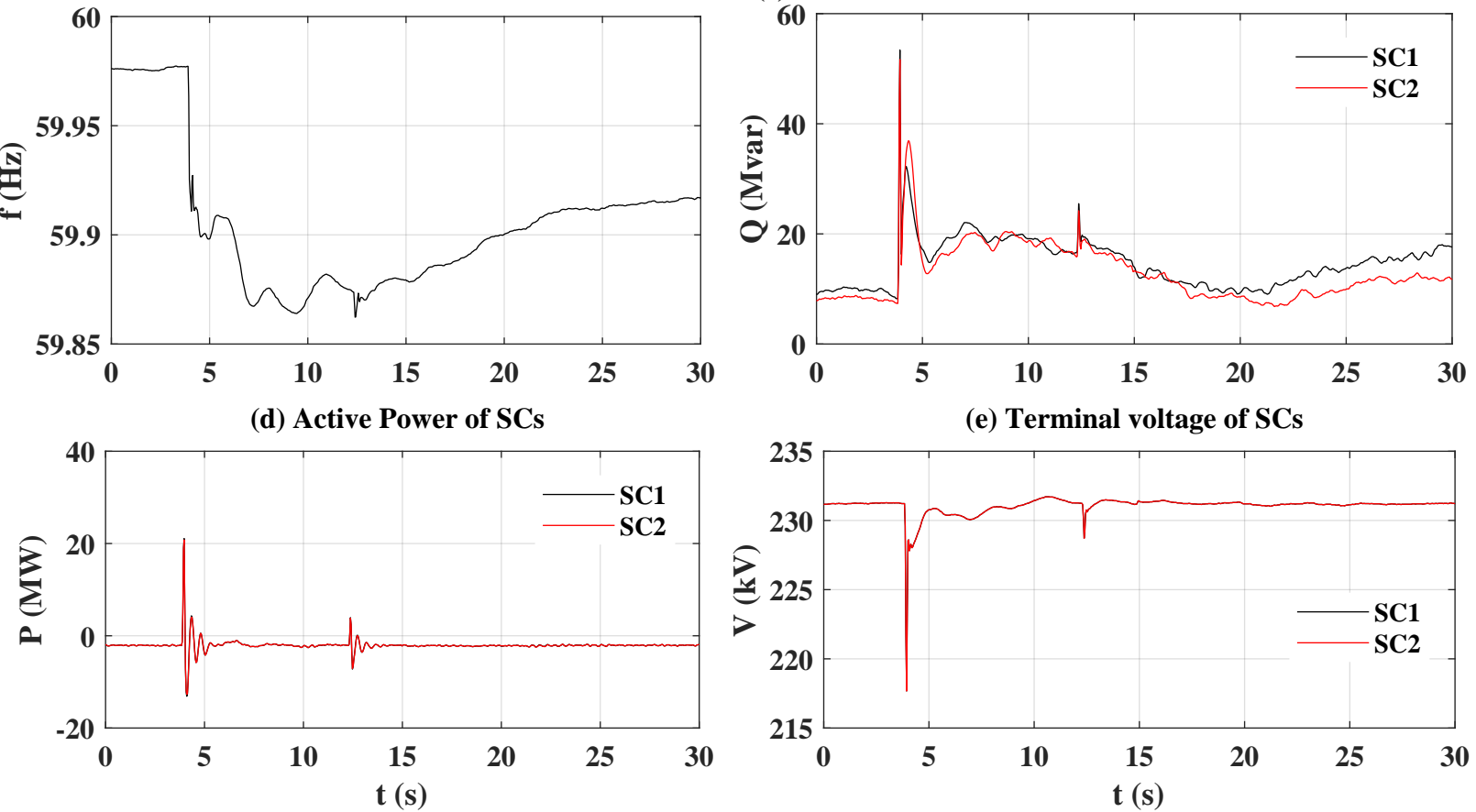

(e) Terminal voltage of SCs

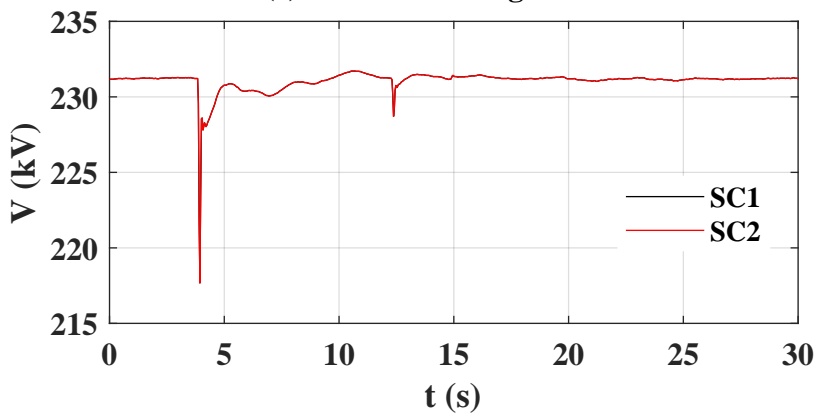

Fig. 2. A solar generator trip incident: (a) ROCOF. (b) System frequency. (c) Reactive power of SCs. (d) Active power of SCs. (e) Terminal voltage of SCs.

synchronous machine, respectively. The system inertia depends on the number of operating rotating machines and the inertia constant of each machine.

The initial ROCOF that is determined by the size of the power imbalance and the system inertia is expressed by

$$
R O C O F=\frac{f_{0}}{2 H_{s y s}} \frac{\Delta P}{S_{s y s}}
$$

where $\Delta P$ is the disturbance size; $f_{0}$ is the nominal system frequency.

A sudden change in load or generation causes a change in the generation-demand equilibrium. The system inertia constant plays a vital role in the first few seconds, after that primary control picks up the frequency deviation by controlling the governor to return the frequency to an acceptable operating value within $30 \mathrm{~s}$. A higher inertia constant results in a lower rate of change of frequency (ROCOF), which gives time to the primary control regulating the power output.
When the system operates with high renewable energy production, high importing HVDC links, and phasing out of conventional power plants, the system inertia reduces significantly that makes the frequency dynamics faster and more vulnerable. This may result in an activation of underfrequency load shedding or ROCOF-operated protection relays for tripping transmission lines. As a result, the system freely gets split and more challenging to operate. Cascading failure or even system blackout may therefore occur.

California power system uses a large amount of renewable energy reaching around $70 \%$ during the peak time of solar radiation [15]. Solar generation is the highest supply with nearly $68 \%$ of the entire amount of renewable sources as shown in Fig. 1. Solar plants are a non-rotational generator which supplies no inertia for the grid during disturbances. The lack of inertia and short-circuit power support is more serious and makes frequency stability jeopardized for the system. 
TABLE I. A COMPARISON OF SC FEATURES WITH FACTS DEVICES.

\begin{tabular}{l|l|l|l|l}
\hline- & MSC/MSR & SC & SVC \\
\hline \hline Application & $\begin{array}{l}\text { Compensation for } \\
\text { predictable load changes }\end{array}$ & $\begin{array}{l}\text { Provision of short-circuit power and dy- } \\
\text { namic compensation and voltage recov- } \\
\text { ery during faults }\end{array}$ & $\begin{array}{l}\text { Fast dynamic compensation } \\
\text { and voltage recovery during } \\
\text { faults }\end{array}$ & $\begin{array}{l}\text { Fast dynamic compensation and } \\
\text { voltage recovery during faults }\end{array}$ \\
\hline Inertia & No contribution & $\begin{array}{l}\text { Lower than a power generator but sig- } \\
\text { nificant }\end{array}$ & No contribution \\
\hline Short-circuit contribution & No contribution & $\begin{array}{l}3 \text { to } 5.5 \text { times the rated power as sub- } \\
\text { transient }\end{array}$ & No contribution \\
\hline Harmonics & Susceptible to harmonics & Not susceptible to harmonics & TCR is source of harmonics & Harmonically self-compensated \\
\hline V/I characteristics & No response & Good over- and under-voltage capacity & Good over-voltage capacity & Good under-voltage capacity \\
\hline Response time & $2-5$ cycles & Seconds & $2-3$ cycles \\
\hline
\end{tabular}

\section{B. Synchronous condenser}

$\mathrm{SC}$ is a synchronous generator without a prime mover which has been playing an important role in reactive power compensation and keeping voltage stability in power systems. By varying the field excitation current, SC can operate at over-excited or under-excited modes to supply/absorb reactive power to/from the network that can provide essential dynamic voltage support during disturbances or keep the system power factor at a specified level.

Furthermore, SC can also support the short-circuit capacity to the network that can improve system interconnections, facilitates system protection and enhances the operation of modern power electronics installations.

Because SC is a rotational machine, inertia is an inherent feature of SC which is able to enhance the stability of generators located closely. The kinetic energy stored in its rotating mass is available as an active power source that can absorb and inject for the system frequency regulation during disturbances [16]. For example, when a generator is suddenly tripped, the SC will supply the rotational energy to the grid to against the frequency declination. On the contrary, when the load suddenly decreases and causes active power imbalance, $\mathrm{SC}$ will absorb the extra energy from the network to halt the frequency increase. As a result, SC can improve frequency stability for the system in terms of voltage, inertia, and short-circuit power support. A brief summary of SC features compared to FACTS devices is presented in Table I.

\section{CASE STUDY}

In this section, a solar generator trip event and a transmission line trip based on the phasor measurement unit supplied by the local operator are investigated to validate the benefit of SC in terms of frequency stability and dynamic voltage support.

\section{A. A PV plant trip}

1200-MW solar photovoltaic (PV) resources in the Southern California system disconnected based on a perceived system frequency below $57 \mathrm{~Hz}$ which was due to the PLL indicating a near instantaneous frequency during the transient/distorted waveform period as less than the threshold. Fig. 22 shows the system responses during the incident. As can be seen clearly, when the PV generation trips, SCs quickly supply kinetic energy around $21 \mathrm{MW}$ to counteract the power imbalance. Consequently, the system frequency and ROCOF are improved as seen in Fig. 2.

As expected, the reactive power of SCs is immediately injected approximately 42 Mvar from 9 Mvar to 51 Mvar to support voltage because of the loss of generation. Therefore, the terminal voltage of SCs and the busbar rapidly recover after the disturbance.

\section{B. A transmission line trip}

Another event with transmission line connected to a generator trip is investigated in this part to verify the benefit of SCs at Talega substation.

Fig. 3 shows the system frequency, ROCOF, terminal voltage of $230 \mathrm{kV}$ and SC responses during the fault. The same pattern is observed in this scenario, the active power and reactive power of SCs rapidly respond to against the frequency excursion and voltage drop, respectively. Hence, the system frequency, ROCOF and terminal voltage of SCs and the busbar quickly recover after the fault as seen clearly in Fig. 3.

The interesting thing should be mentioned here is the terminal voltage of $230 \mathrm{kV}$ busbar at Talega substation where 2 units installed and at Otay Mesa where far away from the SC location. As can be observed in Fig. 3(f), thanks to the quickly support reactive power and active power, the terminal voltage at Talega substation experiences a small drop around $17 \mathrm{kV}$ from $230 \mathrm{kV}$ to nearly $213 \mathrm{kV}$ instead of $100 \mathrm{kV}$ drop from $230 \mathrm{kV}$ to approximately $130 \mathrm{kV}$ of Otay Mesa substation and rapidly settles down at the nominal voltage value.

\section{CONClusion}

In order to ensure a smooth transition from conventional synchronous machine based systems to renewable-based systems which introduces many challenges for power system stability and frequency control, SC is a potential solution in terms of inertia, short-circuit power and voltage support. The paper validates the benefit of SCs which is installed at Talega substation of the California system by San Diego Gas and Electric SDG\&E and Siemens companies. From the measurement data from PMU of two different events, it can be proved that SCs are able to support both voltage and frequency 
(a) Frequency

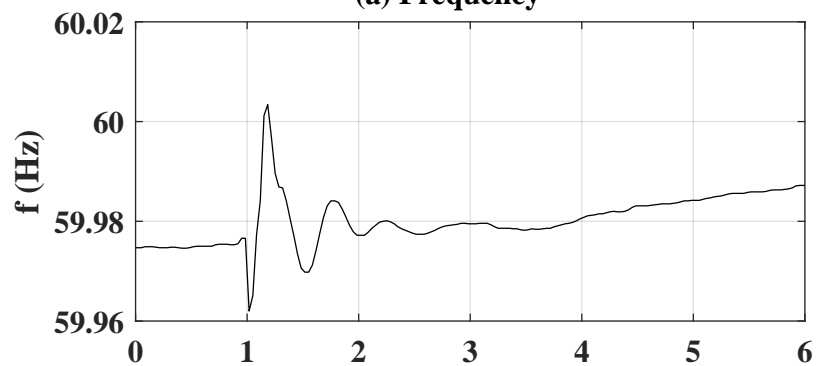

(c) Active Power of SCs

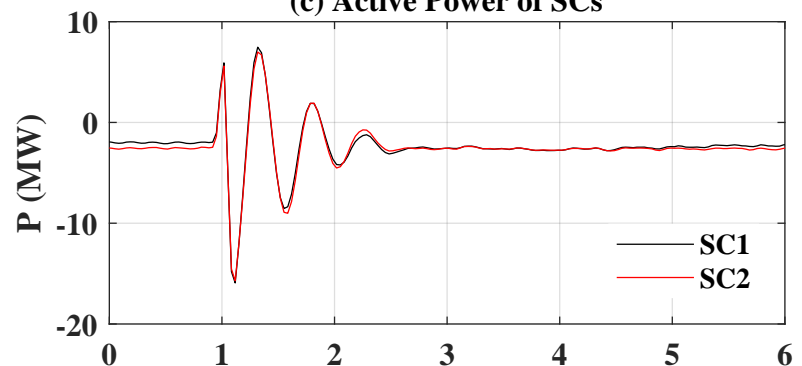

(e) ROCOF

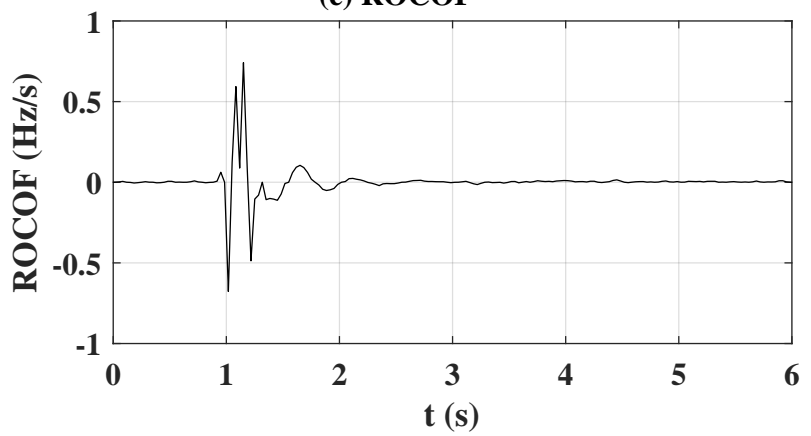

(b) Terminal voltage of SCs

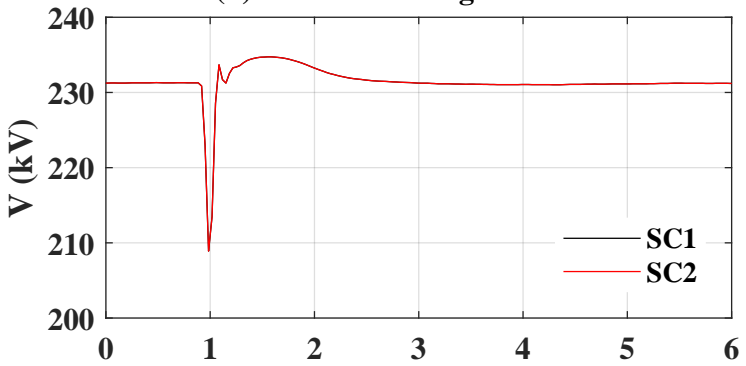

(d) Reactive Power of SCs

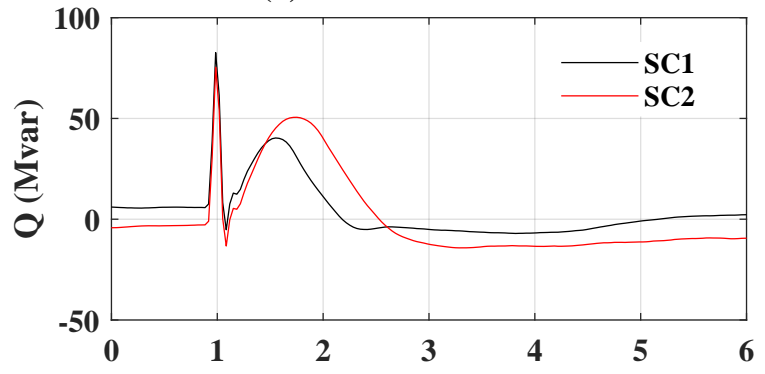

(f) Terminal voltage of Busbar

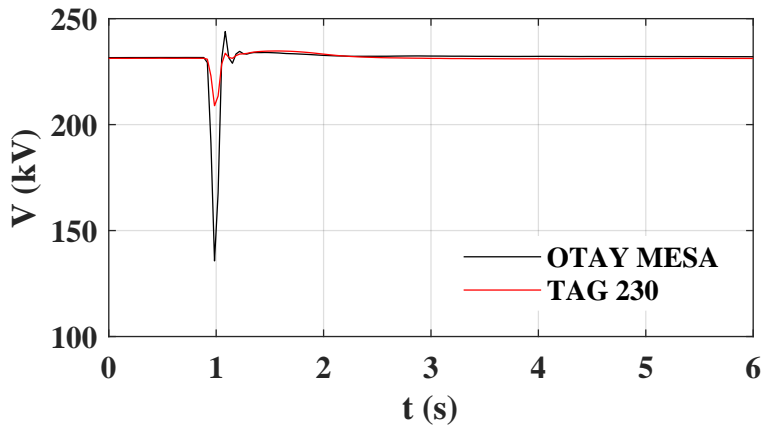

Fig. 3. A transmission line trip incident: (a) System frequency. (b) Terminal voltage of SCs. (c) Active power of SCs. (d) Reactive power of SCs. (e) ROCOF. (f) The voltage of the busbar.

stability to the system which is foreseeable potential solution in the modern power system.

\section{ACKNOWLEDGEMENT}

The authors would like to thank the San Diego Gas and Electric company for their assistance with the collection of the measurement data. This work is supported by Synchronous Condenser Application (SCAPP) project funded by ForskEL program, grant no. 12196 administrated by Energinet.dk [12].

\section{REFERENCES}

[1] IEA, "Medium term renewable energy market report 2015," 2015. [online]. Available: http://www.iea.org/bookshop/708-Medium-TermRenewable-Energy-Market-Report-2015

[2] B. Parsons, M. Milligan, B. Zavadil, D. Brooks, B. Kirby, K. Dragoon, and J. Caldwell, "Grid impacts of wind power: A summary of recent studies in the United States," Wind Energy, vol. 7, pp. 87-108, 2004.

[3] J. C. Smith, M. R. Milligan, E. A. DeMeo, and B. Parsons, "Utility wind integration and operating impact state of the art," IEEE Trans. Power Syst., vol. 22, no. 3, pp. 900-908, Aug. 2007.
[4] Nordic TSOs, "Challenges and opportunities for the Nordic power system," pp. 1-66, 2016. [online]. Available: http://www.svk.se/en/about-us/news/european-electricity-market/reportchallenges-and-opportunities-for-the-nordic-power-system/

[5] NERC, "1200 MW fault induced solar photovoltaic resource interruption disturbance," Jun. 2017. [online]. Available: http://www.nerc.com

[6] California Renewables Portfolio Standard Renewable Generation Integration Cost Analysis: Multi-Year Analysis Results and Recommendations, California Energy Commission, Fin. Rep. CEC-500-2006-064, Jun. 2006. [Online]. Available: http://www.energy.ca.gov/2006publications/CEC-500-2006-064/CEC500-2006-064.pdf.

[7] CAISO, "2016-2017 Transmission Planning Process Unified Planning Assumptions and Study Plan," Feb. 2016. [online]. Available: http://www.caiso.com/Documents/Draft20162017StudyPlan.pdf

[8] S. Nakamura, T. Yamada, T. Nomura, M. Iwamoto, Y. Shindo, S. Nose, A. Ishihara, and H. Fujino, "30 MVA superconducting synchronous condenser: Design and its performance test results," IEEE Transactions on Magnetics, vol. M-21, no. 2, pp. 783-790, Mar. 1985.

[9] S. Kalsi, D. Madura, and M. Ross, "Performance of superconductor dynamic synchronous condenser on an electric grid," in Proc. 2005 IEEE/PES Transmission and Distribution Conference and Exposition, 
Dalian, China, Aug. 23-25, 2005, pp. 1-5.

[10] Siemens, "The stable way synchronous condenser solutions," 2014. [online]. Available: http://www.energy.siemens.com/ru/pool/hq/powertransmission/FACTS/Synchronous-Condenser/SynchronousCondenser.pdf

[11] M. Nedd, C. Booth, and K. Bell, "Potential solutions to the challenges of low inertia power systems with a case study concerning synchronous condensers," in Proc. 2017 52nd International Universities Power Engineering Conference (UPEC), Heraklion, Aug. 28-31, 2017, pp. 1-6.

[12] Synchronous Condensers Application in Low Inertia Systems (SCAPP), 2014. [online]. Available: http://www.scapp.dk/

[13] H. Zhang, J. P. Hasler, N. Johansson, L. ngquist, and H. P. Nee, "Frequency response improvement with synchronous condenser and power electronics converters," in Proc. 2017 IEEE 3rd International Future Energy Electronics Conference and ECCE Asia (IFEEC 2017 ECCE Asia), Kaohsiung, Taiwan, Jun. 3-7, 2017, pp. 1002-1007.

[14] P. E. Marken, J. P. Skliutas, P. Y. Sung, K. S. Kim, H. M. Kim, L. H. Sailer, and R. R. Young, "New synchronous condensers for Jeju Island," in Proc. 2012 IEEE Power and Energy Society General Meeting, San Diego, CA, Jul. 22-26, 2012, pp. 1-6.

[15] CAISO, "Monthly renewables performance report-Mar 2018," $2018 . \quad$ [online]. Available: https://www.caiso.com/Documents/MonthlyRenewablesPerformanceReportMar2018.html

[16] H. T. Nguyen, G. Y. Yang, A. H. Nielsen, and P. H. Jensen, "Frequency stability improvement of low inertia systems using synchronous condensers," in Proc. 2016 IEEE International Conference on Smart Grid Communications, Sydney, Australia, Nov. 6-9, 2016. 